Arq. Bras. Med. Vet. Zootec., v.71, n.2, p.631-639, 2019

\section{Parâmetros fisiológicos e bioquímicos de equinos em treinamento de três tambores: pós-condicionamento, pós-percurso e pós-descanso}

[Physiological and biochaemical parameters of horses in three-barrel training: post-warm-up, post-exercise and post-rest]

C.L.N. Gomes ${ }^{1}$, J.D. Ribeiro Filho ${ }^{2}$, L.P. Silva ${ }^{3}$, R.M.C. Aranha ${ }^{4}$, F.J. Moraes Júnior ${ }^{1}$, J.K.M. Cardoso ${ }^{5}$, L.C. Monteiro ${ }^{6}$

${ }^{1}$ Universidade Estadual do Maranhão - UEMA - Departamento de Clínicas Veterinárias - São Luís, MA

${ }^{2}$ Universidade Federal de Viçosa - UFV - Departamento de Veterinária - Viçosa, MG

${ }^{3}$ Médica veterinária autônoma - Brasil

${ }^{4}$ Secretaria de Estado, Agricultura, Pecuária e Pesca - SAGRIMA - São Luís, MA

${ }^{5}$ Universidade Estadual do Maranhão - UEMA - Pós-graduação em Ciência Animal - São Luís, MA

${ }^{6}$ Universidade Federal de Viçosa - UFV - Pós-graduação em Medicina Veterinária - Viçosa, MG
C.L.N. Gomes 1

http://orcid.org/0000-0003-3156-1225 J.D. Ribeiro Filho2

$/ 0000-0001-5223-9310$ L.P. Silva3

http://orcid.org/0000-0002-8412-3950 R.M.C. Aranha4 http://orcid.org/0000-0003-2435-0446 F.J. Moraes Júnior1 http://orcid.org/0000-0002-7431-1835 J.K.M. Cardoso5 http://orcid.org/0000-0003-1904-8410 L.C. Monteiro6

http://orcid.org/0000-0003-3391-5947

\title{
RESUMO
}

Foram avaliados parâmetros fisiológicos e bioquímicos em equinos Quarto de Milha durante treinamento de três tambores, antes do condicionamento (T0), após o condicionamento (T1), após um percurso (T2), após descanso do percurso, por 20 minutos (T3) e após descanso do percurso, por 40 minutos (T4). Os parâmetros físicos avaliados foram: frequência cardíaca (FC), frequência respiratória (FR), temperatura retal (TR) e tempo de enchimento capilar (TEC); e os bioquímicos: sódio, potássio, cloreto, cálcio total, ureia, creatinina, osmolaridade, creatinaquinase, aspartato transaminase, proteínas totais (PT), glicose e lactato. A FC, a FR e a TR aumentaram após o percurso (T2), mas foram recompostas após 40 minutos de descanso. A concentração do lactato pouco aumentou após o condicionamento, mas altas concentrações ocorreram após o percurso (T2), e embora ele tenha diminuído após 20 (T3) e 40 minutos (T4) do percurso, ainda permaneceu acima dos limites normais. Nos demais parâmetros, não houve variações significativas. Concluiu-se que, ao final de um percurso de três tambores, o exercício sob máxima intensidade não ocasionou variações bioquímicas significativas nos equinos, exceto para o lactato, pois gerou uma hiperlactatemia que não foi restaurada até 40 minutos de descanso pós-percurso, mesmo com os parâmetros físicos já recompostos do esforço.

Palavras-chave: equino, exercício, treinamento, bioquímico, tambor

\begin{abstract}
Physiological and biochemical parameters were evaluated in Quarter Horse during three-barrel training, in three times: TO (before warm-up), T1 (after warm-up), T2 (after completing the exercise, performing only one course), T3 (after resting for 20 minutes of the course), and T4 (after resting for 40 minutes of the course). The parameters evaluated were: heart rate $(H R)$, respiratory rate $(R R)$, rectal temperature $(R T)$ and capillary filling time (ECT); Serum concentrations of sodium, potassium, chloride, total calcium, BUN, creatinine, osmolarity, creatine kinase, aspartate transaminase; Plasma concentrations of

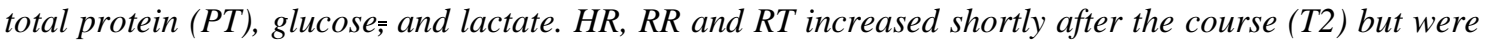
restored after 40 minutes of rest. Lactate concentration increased after conditioning, but at low concentrations, but high levels occurred after the course (T2), and although decreased after 20 (T3) and 40 minutes (T4) of the course, it was still above normal limits. There were no significant changes in the other parameters. At the end of a single course of three-barrel, the exercise of maximum intensity did not cause significant biochemical variations in horses, except for lactate, which increased to levels of hyperlactatemia, and was not restored until 40 minutes of rest, even with the physical parameters already recovered.
\end{abstract}


Keywords: equine, exercise, training, biochemist, barrel

INTRODUÇÃO

Testes de desempenho do equino em atividades atléticas são fundamentais para a compreensão da capacidade da adaptação desses animais ao exercício. Isso é possível e valioso avaliando-se parâmetros fisiológicos, hematológicos e bioquímicos do equino em treinamentos ou em competições (Bis-Wencel et al., 2012; Kupczynski e Spitalniak, 2015).

Os processos metabólicos variam conforme a intensidade e a duração do exercício para prover energia pelas vias aeróbica ou anaeróbica. Nas modalidades equestres cujo exercício físico é de alta intensidade e curta duração, há mecanismos metabólicos com rápido consumo de energia, predominando o metabolismo anaeróbico (Sécani e Léga, 2009), como exemplo, a modalidade equestre Três Tambores (3Tb).

$\mathrm{Na} 3 \mathrm{~Tb}$, o conjunto "homem e cavalo" deve contornar, em menor tempo possível, três tambores dispostos em um percurso triangular, havendo pena por tambor derrubado (Coelho et al., 2011). A raça equina com destaque na $3 \mathrm{~Tb}$ é a Quarto de Milha (QM). Esses animais empreendem rápidas largadas e alcançam alta velocidade em curta distância (Coelho et al., 2011; Carvalho, 2015). Possuem fibras musculares de contração rápida, baixa capacidade oxidativa e com grande capacidade glicolítica_(Silva et al., 2013).

Quanto mais intenso for o exercício, maior a demanda energética. Em um exercício de nível moderado, há exigência de mais consumo de glicose pelo organismo, e se a atividade for intensificada ainda mais, o mecanismo oxidativo pode não conseguir prover oxigênio suficiente às células. Então, o ATP passa a ser gerado por processos anaeróbicos envolvendo glicólise (Sécani e Léga, 2009), como uma via rápida de síntese de ATP pela quebra parcial de glicose e/ou de glicogênio muscular (Botteon, 2012). O produto final desse metabolismo glicolítico é o lactato, gerado do processo de ionização do ácido láctico, no qual há também liberação de próton $\mathrm{H}^{+}$(hidrogênio). $\mathrm{O}$ aumento excessivo das concentrações deste no organismo é denominado de acidose lática (Botteon, 2012). Por isso, a avaliação da função muscular recebe muita importância no equino atleta e pode ser também avaliada mensurando-se, além do lactato, as concentrações séricas de enzimas musculares, como a creatinoquinase (CK) e a aspartato aminotransferase (AST) (Adamu et al., 2012; Di Filippo, 2016). Essa avaliação auxilia na sinalização de queda de desempenho em treinamento ou em competição devido à lesão muscular (Binda et al., 2016).

$\mathrm{O}$ rendimento dos equinos atletas pode ser comprometido em razão da redução da quantidade de eletrólitos durante o exercício (Adamu et al., 2012; Linhares, 2017). Dependendo do exercício, perdas importantes de eletrólitos podem ocorrer pela sudorese e pela variação no fluido plasmático, entre os quais se destacam o sódio, o potássio, o cloreto e o cálcio (Boffi, 2007), e também pelo fato de os eletrólitos serem requeridos por várias funções metabólicas (Assenza et al., 2014). Além disso, suas concentrações no sangue, especialmente as do sódio e do potássio, junto com as da glicose e da ureia, são relevantes na manutenção da osmolaridade sanguínea (Kaneko et al., 1997).

Alterações físicas e bioquímicas podem estar presentes já na fase inicial do treinamento. A avaliação destas desde o início do exercício é importante, pois elas podem indicar um bom ou mau condicionamento físico do animal ou sinalizar uma lesão ou predisposição à lesão já no início do esforço. Objetivando investigar essas possibilidades, o presente estudo avaliou parâmetros físicos e bioquímicos em equinos da raça QM após o condicionamento (aquecimento) e após o primeiro percurso de $3 \mathrm{~Tb}$, durante treinamento, verificando se alterações nos perfis físico e bioquímico dos equinos poderiam já estar presentes na fase inicial do exercício de alta intensidade e curta duração nessa modalidade equestre.

\section{MATERIAL E MÉTODOS}

O experimento foi realizado no haras Chácara Valente, município de Paço do Lumiar, Maranhão (situado a 38 metros de altitude, nas coordenadas geográficas: latitude $2^{\circ} 31^{\prime} 50^{\prime \prime}$ sul, longitude $44^{\circ} 6^{\prime} 19^{\prime \prime}$ oeste).

Foram utilizados 15 equinos (Equus caballus) da raça Quarto de Milha (nove machos castrados e um inteiro, e seis fêmeas), com idades entre 
quatro e nove anos, peso corporal entre 384 e $465 \mathrm{~kg}$, sem evidências clínicas de doença, sob controle ecto e endoparasitário, e adaptados ao treinamento e à prova de três tambores. Todos os equinos recebiam o mesmo tipo de manejo alimentar e sanitário e eram criados e já adaptados no ambiente do haras em que foi realizada a pesquisa. A dieta dos animais consistia de $2 \mathrm{~kg}$ de alfafa peletizada às seis horas; 2,0kg de concentrado: Alfa Super Fibra SUPRA (proteína bruta $14 \%, 2.600 \mathrm{kcal} / \mathrm{kg}$ de energia), associado ao Procavalo melaçado SUPRA (proteína bruta $12 \%, 2.500 \mathrm{kcal} / \mathrm{kg}$ de energia), às sete, 11 e 15 horas; 4,0kg de feno de Tifton 85 às 19h; e água ad libitum.

As avaliações clínicas e as coletas de amostras para exames laboratoriais foram realizadas em cinco tempos durante um treinamento de $3 \mathrm{~Tb}$ : T0 (antes do condicionamento); T1 (imediatamente após o condicionamento ou aquecimento ao trote, durante 10 minutos); T2 (imediatamente após um percurso de $3 \mathrm{~Tb}$, realizado sob galope); T3 (20 minutos em descanso após T2); e T4 (40 minutos em descanso após T2). Entre T0 e T4, os animais permaneceram sob jejum hídricoalimentar. As avaliações dos animais foram feitas em três tardes consecutivas (cinco equinos/dia), com temperatura variando de 30 a $34^{\circ} \mathrm{C}$, e umidade relativa do ar de 71 a $76 \%$ entre o T0 e o T4. O treinamento foi realizado em pista de areia fofa e seca, comumente utilizada nas provas de $3 \mathrm{~Tb}$.

No T0, os animais ainda não se encontravam selados, o que foi somente assim procedido logo após a avaliação física e a coleta das amostras de sangue em T0. Em seguida, foram montados e conduzidos ao passo para a pista de areia do próprio local de percurso, para iniciarem o condicionamento ao trote. Três cavaleiros formaram o conjunto com os equinos, sendo os pesos corporais de cada cavaleiro 64,69 e $71 \mathrm{~kg}$.

Após o condicionamento (T1), os animais foram conduzidos montados e ao trote por uma distância de aproximadamente 50 metros para a avaliação clínica e a coleta de amostras, que ocorreu aproximadamente 30 segundos do T1, e, após 15 minutos, retornaram à pista para a realização do percurso de $3 \mathrm{~Tb}$ sob galope. Da mesma forma ocorreu para as coletas após o percurso (T2), entretanto, após a coleta no T2, os animais ficaram mantidos parados e contidos por cabrestos e à sombra até as avaliações no T3 e no T4, sendo-lhes disponibilizada água à vontade imediatamente após suas frequências cardíacas e respiratórias e a temperatura retal se encontrarem mais restabelecidas, o que foi verificado no $\mathrm{T} 4$

A avaliação clínica dos parâmetros fisiológicos dos equinos nos referidos tempos constou de aferição da frequência cardíaca (FC), da frequência respiratória (FR), da temperatura retal (TR) e do tempo de enchimento capilar (TEC).

As amostras de sangue foram coletadas após antissepsia por venopunção jugular, utilizando-se agulhas $25 \mathrm{~mm} \times 0,8 \mathrm{~mm}$, por sistema a vácuo, em frascos contendo fluoreto de sódio para obtenção do plasma (Frasco siliconizado a vácuo - 5mL fluoreto de sódio - Vacuum II), e em frascos siliconizados sem anticoagulante para obtenção do soro (Frasco siliconizado a vácuo $-10 \mathrm{~mL}$ sem anticoagulante - Vacuum II). As alíquotas do soro e do plasma foram mantidas congeladas a $-20^{\circ} \mathrm{C}$ até o momento das análises laboratoriais. No soro, foram mensurados o sódio e o potássio por fotometria de chama (Fotômetro de chama B462 - Micronal, São Paulo, Brasil). Por multianalisador bioquímico (HumanStar 300; Human GmbH, Wesbaden, DEU), foram determinados, no plasma, a glicose (Gli) e o lactato (Lac), e, no soro, o cloreto $(\mathrm{Cl})$, o cálcio total (tCa), as proteínas séricas totais $(\mathrm{PT})$, a creatinina (Cre), a ureia, a creatinaquinase (CK) e o aspartato transaminase (AST). A osmolaridade sérica foi mensurada em osmometro (Advanced Micro-Osmometer Model 3320; Advanced Instruments Inc., Norwood, MA, USA).

$\mathrm{Na}$ análise estatística, o delineamento experimental foi inteiramente ao acaso, com cinco tratamentos em 15 repetições. Os dados para as variáveis estudadas foram submetidos ao teste de normalidade. Os dados normais e os normalizados, mediante transformações matemáticas (logarítmicas e arco seno), foram submetidos à análise de variância (ANOVA) e ao Teste de Tukey na probabilidade de 5\%. As análises foram executadas por meio do programa Statistical Analysis System (SAS Institute Inc., 2015). A pesquisa foi aprovada pela Comissão de Ética e Experimentação Animal - CEEA do Curso de Medicina Veterinária da Universidade Estadual do Maranhão - Uema, conforme protocolo n. 10/2016. 


\section{RESULTADOS E DISCUSSÃO}

$\mathrm{Na}$ avaliação inicial (T0), nenhum animal apresentou qualquer comportamento indicativo de excitação, medo ou dor, e a FC e a FR estavam em limites normais para equinos em repouso (Tab. 1). A FC pode aumentar rapidamente devido ao estresse por excitação, medo, dor ou manuseios inadequados antes da realização do exercício físico (Boffi, 2007). Então, é presumível que os animais do presente estudo não estiveram sob esses fatores de estresse citados.

Tabela 1. Valores médios e desvios-padrão da frequência cardíaca (FC), da frequência respiratória (FR), da temperatura retal (TR) e do tempo de repleção capilar (TEC) de equinos Quarto de Milha, durante treinamento de três tambores

\begin{tabular}{ccccc}
\hline \multirow{2}{*}{ Tempos } & \multicolumn{4}{c}{ Parâmetros físicos } \\
\cline { 2 - 5 } & FC & FR & TR & TEC \\
& $30-40 \mathrm{bpm} *^{\mathrm{C}}$ & $18-20 \mathrm{rpm}$ & $37,0-39,0^{\circ} \mathrm{C}$ & $1,0-1,5 \mathrm{seg}$ \\
\hline T0 & $40,33 \pm 3,84^{\mathrm{C}}$ & $20,26 \pm 3,15^{\mathrm{C}}$ & $37,61 \pm 0,46^{\mathrm{B}}$ & $1,30 \pm 0,45^{\mathrm{A}}$ \\
T1 & $65,73 \pm 13,6^{\mathrm{AB}}$ & $43,40 \pm 13,46^{\mathrm{AB}}$ & $38,65 \pm 0,48^{\mathrm{AB}}$ & $1,40 \pm 0,49^{\mathrm{A}}$ \\
T2 & $84,66 \pm 11,65^{\mathrm{A}}$ & $51,86 \pm 13,19^{\mathrm{A}}$ & $38,90 \pm 0,55^{\mathrm{A}}$ & $1,50 \pm 0,35^{\mathrm{A}}$ \\
T3 & $58,86 \pm 8,35^{\mathrm{B}}$ & $39,33 \pm 10,71^{\mathrm{B}}$ & $38,65 \pm 0,72^{\mathrm{AB}}$ & $1,30 \pm 0,45^{\mathrm{A}}$ \\
T4 & $46,04 \pm 8,06^{\mathrm{BC}}$ & $23,73 \pm 5,47^{\mathrm{C}}$ & $38,60 \pm 0,65^{\mathrm{AB}}$ & $1,30 \pm 0,45^{\mathrm{A}}$ \\
\hline
\end{tabular}

*Valores de referência para equinos adultos em repouso, segundo Speirs (1999): bpm (batimentos por minuto); rpm: respirações por minuto; ${ }^{\circ} \mathrm{C}$ (graus Celsius); seg (segundos). T0 (tempo antes do condicionamento, com os equinos em repouso); T1 (após o condicionamento dos equinos ao trote); T2 (após a realização de um percurso de 3Tb, ao galope); T3 (20 minutos em repouso após T2); T4 (40 minutos em repouso após T2). Letras maiúsculas diferentes na mesma coluna indicam valores diferentes entre si $(\mathrm{P}<0,05)$ pelo teste de Tukey.

Os valores médios da FC, da FR e da TR dos equinos em T0 estavam entre os limites normais referenciados para equinos em descanso e próximos aos de equinos em repouso antes de exercício de $3 \mathrm{~Tb}$ realizado em condições de clima tropical (Binda et al., 2016), como assim era o do local no presente estudo. A FC aumentou gradualmente conforme o aumento da intensidade do exercício, alcançando maior valor médio que o basal (T0) após o condicionamento (T1) $(\mathrm{P}<0,05)$, elevando-se a níveis ainda maiores após o esforço sob maior velocidade no percurso (T2) $(\mathrm{P}<0,05)$ (Tab. 1) e diminuindo, também gradativamente, após ter cessado o esforço físico em T3 e T4, o que corrobora Bogossian et al. (2017), que relataram ocorrência de aumento linear da FC em consequência do aumento progressivo da intensidade do exercício.

A FR dos equinos também aumentou gradativamente com o exercício, e já se encontrava aumentada, após o condicionamento, ao redor de $100 \%(\mathrm{P}<0,05)$ em relação ao tempo basal (T0) (Tab. 1). Maior aumento foi verificado após o percurso $(\mathrm{P}<0,05)$, diminuindo no T3, embora ainda elevada neste, e somente retornando a valores de repouso após 40 minutos de descanso ou T4 (Tab. 1). Esse comportamento da FR ocorre porque, durante o exercício, o volume-minuto respiratório aumenta em relação linear com a carga de trabalho e o nível de treinamento, podendo alcançar 20 vezes a mais os valores de repouso, o que é importante e necessário para aumentar a hematose, a perfusão alveolar e capilar, e, além disso, favorecer a perda de calor do corpo, que aumenta no exercício (Boffi, 2007), o que ocorreu significativamente nos equinos no T2 $(\mathrm{P}<0,05)$ da presente pesquisa (Tab. 1) devido ao aumento da temperatura corpórea.

O TEC não se alterou $(\mathrm{P}<0,05)$ entre os tempos, embora clinicamente tenha aumentado no T2. Tal fato está relacionado com a perda de líquidos do corpo, que implica a diminuição da perfusão tecidual, aumentando o TEC (Speirs, 1999). 
Após o fim do exercício, a FC, a FR, a TR e o TEC retornaram gradativamente até estarem no T4 em níveis próximos ao do tempo basal ou T0 (Tab. 1).

As concentrações do sódio sérico permaneceram entre os limites normais, e não houve variação significativa entre os momentos avaliados $(\mathrm{P}>0,05)$ (Tab. 2). Tais resultados demonstram que o grau de esforço no exercício até um primeiro percurso de $3 \mathrm{~Tb}$ não ocasiona variação do sódio sérico. Resultado similar ocorreu em QM submetidos somente a uma única bateria de prova de laço em dupla, que, assim como a prova de $3 \mathrm{~Tb}$, caracteriza-se por exercício de alta intensidade e curta duração (Coelho et al., 2011). Martins et al. (2017) também constataram a não variação significativa do sódio sanguíneo em equinos Mangalarga Marchador após prova de marcha, que, por sua vez, tem tempo de prova maior que o do exercício de três tambores. Tal fato favorece maior perda hídrica e aumento de sódio sérico, como constatado por Linhares et al. (2017). Estes pesquisadores atribuíram como justificativa para esse achado a possibilidade de equinos com bom condicionamento físico e adaptados ao esforço físico terem boa capacidade fisiológica para regular e equivaler a perda hídrica e natrêmica, mantendo a concentração de sódio do sangue normal durante o exercício. Isso é coerente, uma vez que o sódio é o mais importante soluto para a manutenção da osmolaridade e do equilíbrio iônico corpóreo. Os rins reabsorvem o sódio para manter a osmolaridade do sangue em concentrações normais. Além disso, é necessário que haja adequado controle da remoção e absorção renal do cátion sódio para evitar ganhos ou perdas inadequadas dele, como também dos ânions cloreto $\left(\mathrm{Cl}^{-}\right)$e bicarbonato $\left(\mathrm{HCO}_{3}{ }^{-}\right)$que o acompanham, para manter o equilíbrio iônico que influi diretamente sobre o $\mathrm{pH}$ corpóreo, o volume do fluido extracelular, a pressão arterial e a perfusão dos órgãos (Palmer e Schnermann, 2015).

Embora a concentração do potássio sérico venha a ser mais elevada após o condicionamento (T1), ela não variou $(\mathrm{P}>0,05)$ com relação ao T0 (Tab. 2). Segundo Boffi (2007), a saída do potássio da célula é proporcional à intensidade do exercício e da contração muscular, pois o potássio é um dos principais mediadores para a vasodilatação dos músculos durante o exercício. Entretanto, no presente estudo, o potássio não aumentou após o esforço intenso do percurso (T1); ao contrário disso, estava próximo ao basal e diminuiu ainda mais no $\mathrm{T} 3$, diferenciando-o do $\mathrm{T} 1 \quad(\mathrm{P}<0,05)$ (Tab. 2), o que pode estar relacionado ao rápido transporte do potássio pela $\mathrm{Na}^{+}, \mathrm{K}^{+}$-ATPase para o interior da célula muscular (Boffi, 2007), um eficaz mecanismo de recaptação do potássio nos músculos dos equinos, com capacidade para absorver o excesso de potássio antes liberado pela intensidade do esforço muscular (Assenza et al., 2014).

Tabela 2. Valores médios e desvios-padrão das concentrações de sódio $\left(\mathrm{mMol}^{-1}\right)$, potássio $\left(\mathrm{mMol} \mathrm{L}^{-1}\right)$, cloreto $\left(\mathrm{mMol}^{-1}\right)$ e cálcio total $\left(\mathrm{mMol} \mathrm{L}^{-1}\right)$ séricos de equinos, durante treinamento de três tambores

\begin{tabular}{ccccc}
\hline & \multicolumn{4}{c}{ Parâmetros bioquímicos } \\
\cline { 2 - 5 } Tempos & Sódio & Potássio & Cloreto & Cálcio total \\
& $132-152 \mathrm{mMol} \mathrm{L}^{-1^{*}}$ & $2,4-4,7 \mathrm{mMol} \mathrm{L}^{-1}$ & $99-109 \mathrm{mMol} \mathrm{L}^{-1}$ & $2,80-3,40 \mathrm{mMol} \mathrm{L}^{-1}$ \\
\hline T0 & $144,06 \pm 5,53^{\mathrm{A}}$ & $5.04 \pm 0,49^{\mathrm{AB}}$ & $97,80 \pm 3,14^{\mathrm{A}}$ & $2,95 \pm 0,15^{\mathrm{A}}$ \\
T1 & $144,46 \pm 5,70^{\mathrm{A}}$ & $5,18 \pm 0,84^{\mathrm{A}}$ & $97,53 \pm 2,87^{\mathrm{A}}$ & $2,90 \pm 0,59^{\mathrm{A}}$ \\
T2 & $145,73 \pm 7,30^{\mathrm{A}}$ & $5,05 \pm 0,63^{\mathrm{AB}}$ & $97,06 \pm 4,02^{\mathrm{A}}$ & $3,01 \pm 0,24^{\mathrm{A}}$ \\
T3 & $144,20 \pm 4,00^{\mathrm{A}}$ & $4,53 \pm 0,49^{\mathrm{B}}$ & $97,66 \pm 2,19^{\mathrm{A}}$ & $2,99 \pm 0,19^{\mathrm{A}}$ \\
T4 & $145,53 \pm 4,24^{\mathrm{A}}$ & $4,58 \pm 0,44^{\mathrm{AB}}$ & $97,93 \pm 2,25^{\mathrm{A}}$ & $3,00 \pm 0,18^{\mathrm{A}}$ \\
\hline
\end{tabular}

*Valores de referência para equinos sadios em repouso, segundo Kaneko et al. (1997) e Boffi (2007). T0 (tempo antes do condicionamento, com os equinos em repouso); T1 (após o condicionamento dos equinos ao trote); T2 (após a realização de um percurso de 3Tb, ao galope); T3 (20 minutos em repouso após T2); T4 (40 minutos em repouso após T2). Letras maiúsculas diferentes na mesma coluna indicam valores diferentes entre si $(\mathrm{P}<0,05)$ pelo teste de Tukey.

Não ocorreu variação na concentração de cloreto entre os tempos estudados $(\mathrm{P}>0,05)$, o qual permaneceu nos limites normais de repouso (Tab. 2). É provável que grandes perdas de cloreto ocorram principalmente em razão da sua eliminação no suor dos equinos somente quando estes são submetidos a exercícios mais 
prolongados, como verificado em equinos sob treinamento de marcha (Donner, 2013).

Também não ocorreu alteração na concentração sérica do cálcio total $(\mathrm{P}>0,05)$, e, em todos os momentos, esta permaneceu entre os valores de referência para equinos sadios em repouso (Tab. 2). É possível que, no presente estudo, não tenha ocorrido diminuição de cálcio sérico porque a intensidade no $3 \mathrm{~Tb}$ ainda é menor quando comparado a exercícios de esforço por tempo mais duradouro, como ocorrido em treino de marcha com cavalos da raça Mangalarga Marchador, quando foram observados níveis de cálcio aumentados após treinamentos (Donner, 2013) nos quais o tempo de atividade é muito mais prolongado do que no de $3 \mathrm{~Tb}$. Assim, como os equinos do presente estudo estavam em bom condicionamento físico e adaptados a treinamento ou prova de $3 \mathrm{~Tb}$, é possível que a capacidade de manutenção das suas concentrações séricas de sódio, potássio, cloreto e cálcio fosse bem regulada e/ou que suas perdas no suor tenham sido muito pequenas.

Tabela 3. Valores médios e desvios-padrão das concentrações séricas das proteínas plasmáticas totais (PT), ureia $\left(\mathrm{mg} \mathrm{dL}^{-1}\right)$, creatinina $\left(\mathrm{mg} \mathrm{dL}^{-1}\right)$ e osmolaridade mensurada (mMol L $\left.{ }^{-1}\right)$ de equinos, durante treinamento de três tambores

\begin{tabular}{ccccc}
\hline \multirow{2}{*}{ Tempos } & \multicolumn{3}{c}{ Parâmetros } \\
\cline { 2 - 5 } & \begin{tabular}{c} 
PT \\
\cline { 2 - 4 } T0
\end{tabular} & $\begin{array}{c}\text { Ureia } \\
2-7,9 \mathrm{mg} \mathrm{dL}^{-1 *}\end{array}$ & $\begin{array}{c}\text { Creatinina } \\
1,1-1,9 \mathrm{mg} \mathrm{dL}^{-1}\end{array}$ & $\begin{array}{c}\text { Osmolaridade } \\
270-310 \mathrm{mMol}^{-1}\end{array}$ \\
\hline T1 & $6,87 \pm 0,38^{\mathrm{B}}$ & $27,86 \pm 4,91^{\mathrm{A}}$ & $1,84 \pm 0,25^{\mathrm{B}}$ & $281,80 \pm 23,28^{\mathrm{C}}$ \\
T2 & $7,21 \pm 0,55^{\mathrm{AB}}$ & $27,87 \pm 4,17^{\mathrm{A}}$ & $1,90 \pm 0,26^{\mathrm{AB}}$ & $283,07 \pm 7,43^{\mathrm{BC}}$ \\
T3 & $7,60 \pm 0,73^{\mathrm{A}}$ & $28,73 \pm 3,79^{\mathrm{A}}$ & $2,04 \pm 0,26^{\mathrm{AB}}$ & $295,33 \pm 15,21^{\mathrm{A}}$ \\
T4 & $7,08 \pm 0,36^{\mathrm{AB}}$ & $28,80 \pm 3,26^{\mathrm{A}}$ & $2,16 \pm 0,46^{\mathrm{A}}$ & $284,87 \pm 6,73^{\mathrm{BC}}$ \\
\hline
\end{tabular}

*Valores de referência para equinos repouso, segundo Kaneko et al. (1997), Boffi (2007), e Padilha et al. (2017). T0 (antes do condicionamento, com os equinos em repouso); T1 (após o condicionamento ao trote); T2 (após um percurso de 3Tb ao galope); T3 (20 minutos de repouso após T2); T4 (40 minutos de repouso após T2). Letras maiúsculas diferentes na mesma coluna indicam valores diferentes entre si $(\mathrm{P}<0,05)$ pelo teste de Tukey.

A concentração de proteínas totais (PT) aumentou $(\mathrm{P}<0,05)$ no $\mathrm{T} 2$ em relação ao $\mathrm{T} 0$ (Tab. 3). Perda hídrica pelo treinamento ou pelas provas de exercício intenso foi descrita como a provável responsável por aumento na concentração de PT em equinos (Santos, 2006), o que aumenta a osmolaridade do sangue, sendo também a causa do aumento $(\mathrm{P}<0,05)$ da $\mathrm{PT}$ e da osmolaridade no T2, no presente estudo (Tab. 3).

A concentração de ureia não variou entre os tempos $(\mathrm{P}>0,05)$, mas ocorreu discreto aumento nela após o exercício (T2), ficando ainda um pouco mais aumentada no T3 e no T4 em relação ao T0 e ao T1 (Tab. 3). A creatinina sérica também aumentou $(\mathrm{P}<0,05)$ somente no $\mathrm{T} 2$, diferindo em relação ao T0 (Tab. 3). A perda hídrica com subsequente redução do volume plasmático também pode ser responsável pelo aumento na concentração de ureia e creatinina em equinos após prática de exercício físico. Por outro lado, o aumento de produtos resultantes do metabolismo muscular pode causar aumento de creatinina, o que pode estar relacionado com o aumento da liberação de creatina muscular e a sua diminuição na excreção urinária durante a atividade muscular, com a utilização de fosfocreatinina ou com a gliconeogênese aumentada (Boffi, 2007; Santos, 2006). Assim, como os equinos apresentaram aumento nas concentrações de creatinina, que estão relacionadas às perdas hídricas e da $\mathrm{CK}$ relacionadas ao exercício físico, é possível que tanto a perda hídrica quanto a maior liberação de CK tenham favorecido o aumento da creatinina sérica dos animais no T2.

Em T3 e T4, as concentrações da glicose aumentaram $(\mathrm{P}<0,05)$ em relação aos tempos anteriores (Tab. 4). Barbosa et al. (2016) também verificaram aumento da glicose no sangue de equinos imediatamente após exercício de $3 \mathrm{~Tb}$. Tal fato pode estar relacionado à glicogenólise e à gliconeogênese ocorrendo por ação de reguladores do metabolismo energético, com o cortisol e a catecolamina aumentados na circulação e a insulina diminuída, ocasionando, 
por conseguinte, aumento na glicemia (Fonseca et al., 2011; Barbosa et al., 2016).

Embora com variações significativas entre os tempos estudados, a concentração de glicose ficou entre os limites referenciados para equinos sadios em repouso. Faz-se necessário ressaltar que são díspares os achados quanto às concentrações de glicose em equinos após exercícios. Provavelmente essas diferenças estão relacionadas com a intensidade do exercício praticado e o tempo de duração da atividade
(Santos, 2006). A variação no metabolismo da glicose e a manutenção da sua concentração no sangue dependem de vários órgãos, como o fígado, o pâncreas, os músculos, os rins, a adrenal, a hipófise e a tireoide. O fígado produz e libera glicose quando os tecidos dela necessitam, e colabora para a manutenção da glicose em níveis estáveis no sangue. Os músculos também armazenam glicogênio, que é usado durante a contração muscular, e a gliconeogênese ajuda a manter a taxa glicêmica dos equinos durante a atividade física (Lindner, 2000).

Tabela 4. Valores médios e desvios-padrão das concentrações de glicose $\left(\mathrm{g} \mathrm{dL}^{-1}\right)$, lactato (mMol $\left.\mathrm{L}^{-1}\right)$, creatinoquinase $\left(\mathrm{CK} \mathrm{em} \mathrm{U} \mathrm{L}^{-1}\right.$ ) e aspartato transaminase (AST em $\mathrm{U} \mathrm{L}^{-1}$ ) de equinos em treinamento de três tambores

\begin{tabular}{ccccc}
\hline \multirow{2}{*}{ Tempos } & \multicolumn{4}{c}{ Parâmetros } \\
\cline { 2 - 5 } & Glicose & Lactato & CK & AST \\
& $75-115 \mathrm{mg} \mathrm{dL}^{-1} *$ & $1,11-1,78 \mathrm{mMol}^{-1}$ & $100-300 \mathrm{UI} \mathrm{L}^{-1}$ & $226-366 \mathrm{UI} \mathrm{L}^{-1}$ \\
\hline T0 & $100,86 \pm 9,86^{\mathrm{B}}$ & $0,68 \pm 0,26^{\mathrm{C}}$ & $202,53 \pm 84,00^{\mathrm{A}}$ & $313,73 \pm 108,7^{\mathrm{A}}$ \\
T1 & $88,66 \pm 17,36^{\mathrm{B}}$ & $1,12 \pm 0,90^{\mathrm{B}}$ & $212,86 \pm 77,39^{\mathrm{A}}$ & $322,87 \pm 105,39^{\mathrm{A}}$ \\
T2 & $98,93 \pm 10,86^{\mathrm{B}}$ & $14,78 \pm 3,00^{\mathrm{A}}$ & $296,40 \pm 164,30^{\mathrm{A}}$ & $353.47 \pm 85,92^{\mathrm{A}}$ \\
T3 & $113,20 \pm 9,74^{\mathrm{A}}$ & $8,69 \pm 2,65^{\mathrm{A}}$ & $233,60 \pm 100,62^{\mathrm{A}}$ & $327,20 \pm 91,93^{\mathrm{A}}$ \\
T4 & $116,13 \pm 9,00^{\mathrm{A}}$ & $3,46 \pm 1,29^{\mathrm{A}}$ & $229,80 \pm 89,94^{\mathrm{A}}$ & $323,13 \pm 96,29^{\mathrm{A}}$ \\
\hline
\end{tabular}

*Valores de referência para equinos em repouso segundo Kaneko et al. (1997), Boffi (2007), e Padilha et al. (2017). T0 (em repouso); T1 (após o condicionamento ao trote); T2 (após um percurso de 3Tb); T3 (após 20 minutos descansando do T2); T4 (após 40 minutos descansando do T2). Letras maiúsculas diferentes na mesma coluna indicam valores diferentes entre si $(\mathrm{P}<0,05)$ pelo teste de Tukey.

Concentrações normais de lactato plasmático estão entre 1,11 e $1,78 \mathrm{mMol} \mathrm{L}^{-1}$ (Kaneko et al., 1997), sendo aceitos valores menores que

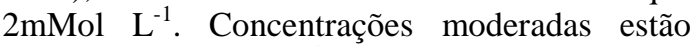
entre 2,5 e $4 \mathrm{mMol} \mathrm{L}^{-1}$, e altas quando acima de $4 \mathrm{mMol} \mathrm{L}^{-1}$ (Santos, 2006). Houve um leve aumento $(<2)$ na concentração do lactato plasmático no T1 $(\mathrm{P}<0,05)$. Concentração elevada $(>4)$ de lactato ocorreu após o percurso ou T2 $(\mathrm{P}<0,05)$. Após o descanso por 20 minutos (T3), a taxa de lactato estava bem menor que no $\mathrm{T} 2$, porém ainda aumentada $(\mathrm{P}<0,05)$ e reduziu para nível moderado no T4 (Tab. 4). Os valores médios do lactato nos momentos T2 e T3 sinalizaram hiperlactatemia, o que confirma que há predomínio do metabolismo anaeróbio no exercício de alta intensidade, com produção de lactato advinda da glicólise anaeróbica (Caiado et al., 2011).

A redução rápida nos valores de lactato no $\mathrm{T} 3$ e no T4, embora sem retornar ao limite basal, pode estar relacionada ao bom condicionamento dos animais à atividade de $3 \mathrm{~Tb}$, pois os equinos já eram adaptados e competidores nessa modalidade, e equinos treinados apresentam concentrações mais baixas de lactato no pósexercício em relação a equinos não treinados (Caiado et al., 2011). Ferraz et al. (2008) também relataram a tendência de diminuição do lactato para concentrações menores após o exercício e já na fase de desaceleração do exercício ativo e intenso, em equinos realizando exercício em esteira, o que estaria relacionado com a gliconeogênese que ocorre em razão da remoção de lactato muscular e sanguíneo, utilizado como substrato energético.

Os valores de CK e de AST não se diferenciaram em nenhum momento $(\mathrm{P}>0,05)$ e, em todos os momentos, ficaram mantidos em limites normais de referência (Tab. 4). Esses resultados se assemelham ao estudo de Binda et al. (2016), que também não encontraram variação significativa para CK e AST em equinos após percurso de $3 \mathrm{~Tb}$ realizado em condições tropicais e atribuíram tal fato à possibilidade de que os animais estivessem adaptados ao programa de exercício e sem lesão muscular. Da mesma forma, os equinos do presente estudo assim se 
encontravam, sendo animais já adaptados ao exercício semanalmente e a competições, portanto com pré-condicionamento muscular ao esforço físico submetido.

\section{CONCLUSÃO}

Um único percurso de $3 \mathrm{~Tb}$ ocasiona aumento significativo na concentração de lactato plasmático (hiperlactatemia), e o descanso por 40 minutos, embora diminua a lactatemia, ainda não é suficiente para retornar o lactato a limites normais. Por outro lado, não altera os demais parâmetros bioquímicos estudados. As variações nos parâmetros fisiológicos foram decorrentes do esforço físico no exercício de alta intensidade, podendo ser consideradas fisiológicas.

\section{AGRADECIMENTOS}

À Fundação de Apoio à Pesquisa e Desenvolvimento Científico do Maranhão (Fapema); à Chácara Valente (Paço do Lumiar, Maranhão); à Universidade Estadual do Maranhão (Uema); e à Universidade Federal de Viçosa (UFV).

\section{REFERÊNCIAS}

ADAMU, M.A.; NORANIZA, A.; RASEDEE, A. et al. Metabolic responses in endurance horses during racing in relation to uric acid profile, leucocytes, heart rate and plasma biochemical parameters. Vet. Med., v.57, p.591596, 2012.

ASSENZA, A.; BERGERO, D.; CONGIU, F. et al. Evaluation of serum electrolytes and blood lactate concentration during repeated maximal exercise in horse. J. Equine Vet. Sci., vn.34, p.1175-1180, 2014.

BARBOSA, J.P.B.; DENADAI, D.S.; GERARDI, B. et al. Avaliação endoscópica das vias aéreas, do perfil de gases, dos eletrólitos e do equilíbrio ácido-base em equinos submetidos ao treinamento de três tambores, Arq. Bras. Med. Vet. Zootec., v.68, p.1152-1158, 2016.

BINDA, M.B.; TEIXEIRA, F.A.; CARVALHO, R.S. et al. Effects of 3-Barrel Racing Exercise on Electrocardiographic and on Blood Parameters of Quarter Horses. J. Equine Vet. Sci., v.47, p.7176, 2016.
BIS-WENCEL, H.; LUTNICKI, K.; ROWICKA, A.Z. et al. Effort of varying intensity as a fator influencing the variability of selected biochaemical blood parameters of jumping horses. Bull Vet. Inst. Pulawy, v.56, p.25-229, 2012.

BOFFI, F.M. (Ed.). Fisiologia del ejercicio em equinos. Buenos Aires: Inter-Médica, 2007. $307 \mathrm{p}$. 
BOGOSSIAN, PM.; OLIVEIRA, T.M.; HILGERT, A.R. et al. Testes de esforço em cavalos: índices úteis ao ajuste do treinamento. Ciênc. Anim., v.27, p.99-117, 2017

BOTTEON, P.T.L. Lactato na medicina veterinária - atualização conceitual. Rev. Bras. Med. Vet., v.34, p.283-287, 2012.

CAIADO, J.C.C.; PISSINATE, G.L.; SOUZA, V.R.C. et al. Lactacidemia e concentrações séricas de aspartato aminotransferase e creatinoquinase em equinos da raça Quarto de Milha usados em provas de laço em dupla. Pesqui. Vet. Bras., v.31, p.452-458, 2011.

CARVALHO, M.G. Carga de trabalho de equinos da raça Quarto de Milha monitorados com sistema de posicionamento global (GPS) $e$ monitor cardíaco durante exercício de três tambores. 2015, 82f. Dissertação (Mestrado em Biotecnologia Animal) - Faculdade de Medicina Veterinária e Zootecnia, Universidade Estadual Paulista, Botucatú, SP.

COELHO, C.S.; LOPES, P.F.R.; PISSINATI, G. L. et al. Influência do exercício físico sobre sódio e potássio séricos em equinos da raça Quarto de Milha e mestiços submetidos à prova de laço em dupla. Rev. Bras. Ciênc. Vet., v.18, p.32-35, 2011.

DI FILIPPO, P.A.; MARTINS, L.P.; MEIRELES, M.A.D. et al. Differences-induced changes in serum hematologic and biochemical variables in Mangalarga Marchador horses after a marcha gait competition. J. Equine Vet. Sci., v.43, p.18-22, 2016.

DONNER, A.C. Efeitos da ingestão ad libitum de repositor hidroeletrolítico e energético em equinos submetidos ao treinamento de marcha. 2013. 60f. Dissertação (Mestrado em Medicina Veterinária) - Departamento de Veterinária, Universidade Federal de Viçosa, Viçosa, MG.

FERRAZ， G.C.; TEIXEIRA-NETO, A.R.; LACERDA-NETO, J.C. et al. Respostas ao exercício de intensidade crescente em equinos: alterações na glicose, insulina e lactato. Ciênc. Anim. Bras., v.10, p.1332-1338, 2008.

FONSECA L. A.; GIRARDI, F.M.; COELHO, C.S. et al. Influence of chromium supplementation on energy metabolism in horses used in policing activity. Arq. Bras. Med. Vet. Zootec., v.63, p.1175-1180, 2011.
KANEKO, J.J.; HARVEY, J.W.; BRUSS, M.L. (Eds.). Clinical biochemistry of domestic animals. San Diego: Academic Press, 1997. 932p.

KUPCZYNSKI, R.; SPITALNIAK, K. Analysis of acid-base balance as well as hematological and biochemical parameters in horses of combined driving discipline. Arch. Anim. Breed., v.58, p.221-228, 2015.

LINDNER, A. Use of blood biochemistry for positive performance diagnosis of sports horse in pratice. Rev. Méd. Vét., v.151, p.611-618, 2000.

LINHARES, J.M.; DI FILIPPO, P.A.; BOGOSSIAN, P.N. et al. Physical exercise on serum electrolytes and acid base balance in Mangalarga Marchador horses submitted to cavalcade of 4,8 and $20 \mathrm{~km}$. Ciênc. Rural, v.47, p.1-6, 2017

MARTINS, L. P.; DI FILIPPO, P.A.; MEIRELES, M.A.D. et al. Effect of marcha exercise on serum electrolytes and acid base balance in Mangalarga Marchador horses. $J$. Equine Vet. Sci., v.49, p.108-112, 2017.

PADILHA, F.G.F.; DIMACHE, L.A.G.; ALMEIDA, F.Q. et al. Blood biochemical parameters of Brazilian sport horses under training in tropical climate. Rev. Bras. Zootec., v.6, p.678-682, 2017.

PALMER, L.G.; SCHNERMANN, J. Integrated control of na transport along the nephron. Clin. J. Am. Soc. Nephro., v.10, p.76-687, 2015.

SANTOS, V.P. Variações hematobioquímicas em equinos de salto submetidos a diferentes a tipos de protocolos de exercício. 2006. 94f. Dissertação (Mestrado em Ciências Veterinárias) - Faculdade de Medicina Veterinária e Zootecnia, Universidade Federal do Rio Grande do Sul, Porto Alegre, RS.

SAS/STAT software changes and enhancements trhough release 9.4. Care: Statistical Analysis System Institute, 2015.

SÉCANI, A.; LÉGA, E. Fisiologia do exercício em equinos. Nucl. Anim., v.1, p.53-66, 2009.

SILVA, M.A.G.; GOMIDE, L.M.W.; DIAS, D.P. M. et al. Equilíbrio ácido-base em equinos da raça Quarto de Milha participantes da prova dos três tambores. Rev. Bras. Med. Vet., v.35, p.188-192, 2013. 


\section{Gomes et al.}

SPEIRS, V.C. (Ed.). Exame clínico de equinos.

Porto Alegre: Artmed, 1999. 366p. 